\section{Intercoronary communication between the circumflex and right coronary artery}

A 62-year-old hypertensive, dyslipidemic male presented with history of effort angina for 8 months. His baseline ECG was normal, and treadmill test was strongly positive for inducible ischaemia. Transthoracic echocardiogram was normal. A coronary angiogram was subsequently done. Selective injection of the right coronary artery (RCA) showed retrograde filling of the circumflex artery and a tight proximal RCA lesion, whereas, left coronary injection did not fill the RCA due to proximal total occlusion of left circumflex (LCX). In view of LCX occlusion, it was thought that retrogradely filling vessel from the right is a collateral from RCA. However, detailed analysis showed that the retrogradely filling vessel has a larger diameter and straighter course. Thus a possibility of intercoronary communication between RCA and LCX was considered (figure 1 and online supplementary video 1 ). The patient underwent percutaneous coronary intervention to the proximal RCA.

Interarterial communication is very rare in the coronary system. The first documented case was reported by Cheng in 1973. ${ }^{1}$ Two types of intercoronary communication have been

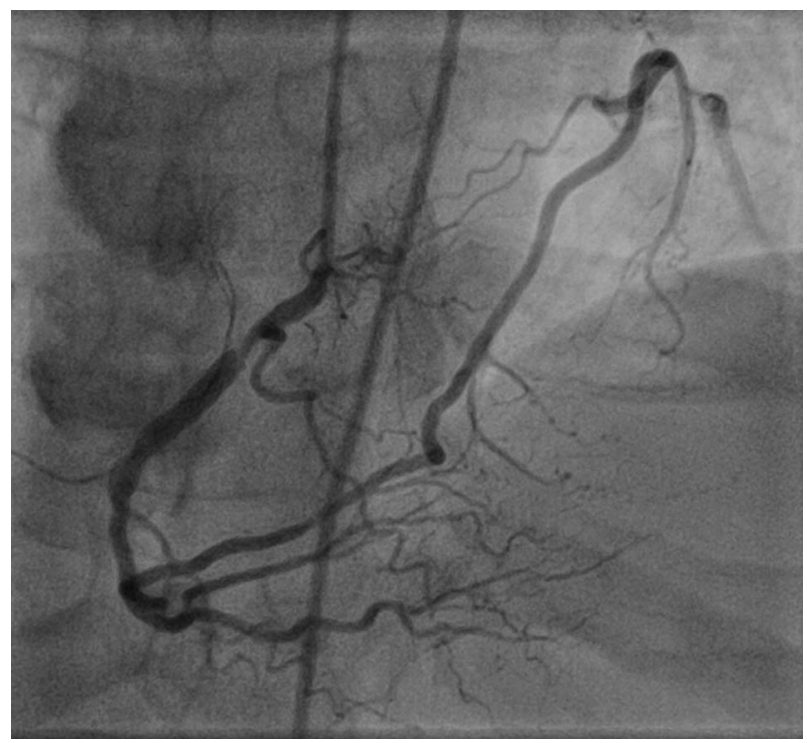

Figure 1 Coronary angiogram showing the retrogradely filling vessel with larger diameter and straighter course, intercoronary communication, between right coronary artery and left circumflex artery. defined: (1) between anterior and posterior interventricular arteries in the distal portion of the posterior interventricular groove and (2) between the distal RCA and circumflex arteries in the posterior atrioventricular groove, as described in our case. Anatomically and angiographically, collateral vessels and intercoronary communication are different. Collaterals develop in the presence of obstructive coronary artery disease, are usually less than $1 \mathrm{~mm}$ in diameter, and appear tortuous and twisted with a corkscrew shape, whereas intercoronary anastomosis in the absence of obstructive lesions tend to be straight or gently curved. Histologically, collaterals that develop in the presence of obstructive coronary artery disease are composed of endothelium supported by poorly organised collagen, muscle and elastic fibres, while intercoronary communications are similar to an epicardial vessel with a well-defined muscular layer. ${ }^{2}$ Persistence of the fetal coronary circulation has been suggested as the underlying mechanism for the development of intercoronary communication. This anomaly can be misinterpreted as a functioning collateral vessel for unrecognised severe proximal coronary artery obstruction. A large collateral vessel, as opposed to a true intercoronary communication, is the likely case if there is a severe stenosis or total occlusion in any coronary artery. A true intercommunication in the coronary system is benign, and may serve as a collateral source in the event that a coronary artery obstruction develops. ${ }^{3}$

\section{K F Rajesh, M P Ranjith, C G Sajeev, M N Krishnan}

Department of Cardiology, Government Medical College, Kozhikode, Kerala, India

Correspondence to Dr K F Rajesh, Department of Cardiology, Government Medical College, Kozhikode, Kerala 673008, India; drrajeshkf@gmail.com

Contributors KFR: substantial contributions to conception and design, acquisition of data. MPR: analysis and interpretation of data. CGS: drafting the article or revising it critically for important intellectual content. MNK: final approval of the version to be published.

\section{Competing interests None.}

Patient consent Obtained.

Provenance and peer review Not commissioned; externally peer reviewed.

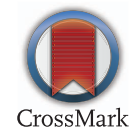

To cite Rajesh KF, Ranjith MP, Sajeev CG, et al. Heart Asia 2013;5:252. doi:10.1136/heartasia-2013-010468

Heart Asia 2013;5:252. doi:10.1136/heartasia-2013-010468

\section{REFERENCES}

1 Cheng TO. Arteriographic demonstration of intercoronary arterial anastomosis in a living man without coronary artery disease. Angiology 1972;23:76-88.

2 Panayiotou H, Perry JM, Norris JW. Intercoronary connection and apical left ventricular hypertrophy: Case report and review of the literature. Cathet Cardiovasc Diagn 1991;24:55-7.

3 Lee S-H, Park S-H, Ji AY, et al. Protective role of intercoronary communication between right coronary artery with chronic total occlusion and Normal Left Circumflex Artery against Recurrent Myocardial Ischemia. J Lipid Atheroscler 2012;1:105-9. 